\title{
Introduction to 1992 Asilomar Conference Papers
}

\author{
Margie A Goldstein ${ }^{1,3}$ and Barbara Bowles Biesecker ${ }^{2}$
}

In the 24 years since the first graduate education program in genetic counseling was established, training program directors have met formally on five occasions to address the educational needs of genetic counselors. The most recent of these meetings was held in 1992 at Asilomar Conference Center in Pacific Grove, California.

The first of these meetings, held in 1974, was an informal meeting of faculty and students from four of the five programs then in existence (Sarah Lawrence, Rutgers University, University of California at Irvine and at Berkeley). A second meeting, held in 1976, also at Asilomar, included representatives from a variety of state, federal, and volunteer health agencies. This kind of representation characterized each of the subsequent meetings. The goal of the 1976 meeting was to identify sources for financial support for the graduate programs. The third meeting, held in 1979 in Williamsburg, Virginia, was sponsored by the Office of Maternal and Child Health $(\mathrm{MCH})$. Four main topics were addressed: recommendations for training curricula, identification of funding sources for genetic counseling services, evaluation mechanisms for genetic counselor training, and continuing education for practicing genetic counselors. The conference proceedings outlined the first guidelines for graduate education in genetic counseling (Walker, 1979).

Eight years after the Williamsburg meeting, Scott et al. (1987) recommended that the guidelines be reviewed in light of the rapidly developing changes in the field of medical genetics. In 1989, the Education

\footnotetext{
${ }^{1}$ Program in Genetic Counseling, University of California, Berkeley, California.

${ }^{2}$ Department of Molecular Medicine and Genetics and Human Genome Center, University of Michigan, Ann Arbor, Michigan.

${ }^{3}$ Correspondence should be directed to Margie A. Goldstein, Program in Genetic Counseling, University of California, 570 University Hall, Berkeley, California 94720.
} 
Committee of the National Society of Genetic Counselors (NSGC) organized a subsequent meeting at Asilomar Conference Center. This fourth meeting was funded by $\mathrm{MCH}$ and the 1979 guidelines for curricula and clinical training were updated (Walker et al., 1990). These minimal guidelines were subsequently endorsed by the Board of the NSGC. The meeting also included workshops on alternative training mechanisms to address the shortage of counselors and the necessity or desirability of doctorate programs in genetic counseling.

The 1989 Asilomar conference participants recommended further exploration of the changes in genetic counseling likely to result from the Human Genome Project with specific attention to three topics: ethnocultural issues in genetic counseling; ethical, legal and social implications of the Human Genome Initiative; and innovative strategies to address the shortage of genetic counselors.

The Board of Directors of the NSGC voted in 1990 to continue to sponsor periodic meetings of training program directors, to review curricula and discuss issues relevant to the training of genetic counselors. A subcommittee of the NSGC Education Committee successfully applied to the Office of Human Genome Research, National Institutes of Health, for ELSI funding. The 1992 Asilomar conference was therefore supported by grant HG00738 and the papers published here were originally presented, or reflect discussions which occurred at this conference. These six papers address the three identified areas of focus: ethnocultural issues in genetic counseling, a survey of training programs and projections for future needs vs. availability, and genetic counseling in the gene mapping era.

\section{REFERENCES}

Scott JA, Walker AP, Eunpu DL, Djurdjinovic L (1988) Genetic counselor training: A review and considerations. Am J Hum Genet 42:191-199.

Walker AP (1979) Asilomar east. Perspect Genet Couns 1:1-4.

Walker AP, Scott JA, Biesecker BB, Conover E, Blake W, Djurdjinovic L (1990) Report of the 1989 Asilomar meeting on education in genetic counseling. Am J Hum Genet 45:1223-1230. 